\title{
Dye separation using a semi-batch foaming process: Process optimization using Taguchi methodology and Grey relational analysis
}

\author{
Tarun Kumar Bharadwaj, Kaushal Naresh Gupta ${ }^{\dagger}$ \\ Department of Chemical Engineering, Jaypee University of Engineering \& Technology, A.B. Road, Raghogarh, Guna- 473226 (M. P.), India
}

\begin{abstract}
Foam fractionation is one of the novel techniques used nowadays for the wastewater treatment. The present paper discusses the removal of methylene blue dye by using a surfactant, sodium dodecyl sulfate, as a collector, by semi-batch foam fractionation technique. The influence of operating variables like aeration rate $\left(150-250 \mathrm{~mL} \cdot \mathrm{min}^{-1}\right)$, liquid height $(600-900 \mathrm{~mL})$, dye concentration $(5-25 \mathrm{ppm})$, $\mathrm{pH}(3-10)$, surfactant dose $(250-2000 \mathrm{ppm})$ on percentage removal, enrichment ratio and surface excess were investigated. The results revealed fairly high percentage removals at various operating conditions due to strong electrostatic interaction between dye and surfactant. Further, in order to augment separation, optimization was performed by employing Taguchi-based experimental design followed by Grey relational analysis (GRA) technique. The optimal conditions were found to be: $150 \mathrm{~mL} \cdot \mathrm{min}^{-1}$ air flow rate, $600 \mathrm{~mL}$ liquid loading and $5 \mathrm{ppm}$ dye concentration for percentage removal of $95.7 \%$ and an enrichment ratio of 7.49. The analysis of variance (ANOVA) suggested dye concentration to be the most influencing operating variable. Lastly, the equilibrium relationship between bulk and surface phase was established which qualitatively indicates as to how much the actual process departs from equilibrium.
\end{abstract}

Keywords: Enrichment ratio, Foam fractionation, Methylene blue, Percentage removal, Sodium dodecyl sulfate

\section{Introduction}

The vast amount of contaminated wastewater generated primarily from the diverse process industries is considered to be one of the colossal worldwide problems which have very seriously been taken up by the researchers and environmentalists in the last one or two decades. One such hazardous pollutant is a synthetic dye that is being substantially used in the textile, tannery, pharmaceutical, cosmetic, food, and paper industries [1-4]. These dyes give rise to production of huge amount of colored wastewater, thus posing serious threat to the water quality and aquatic life [5-7] by significantly impeding the sunlight penetration [8-11]. Also, the complex structure of most of the synthetic dyes makes it stable and hence non-biodegradable [12-16]. There are around 10000 different dyes and pigments with gigantic $7 \times 10^{5}$ tons annual production worldwide, of which approximately 50,000 tons are being directly released into the environment [17-19]. Methylene blue
(MB), an organic dye, generally used for dyeing cotton or silk has been employed in this work. Its harmful health effects include nausea, dizziness, abdominal pain, sweating, etc. [20, 21]. There are various techniques available for the isolation of dyes such as membrane separation [22], oxidation [23], ion exchange [24], coagulation-flocculation [25, 26], flotation [27], adsorption [28-30], precipitation, aerobic and anaerobic biological processes [31]. These techniques usually suffer from economic disadvantages because of the regeneration of adsorbent, high production of sludge and fouling of membranes [32]. Foam fractionation is one such novel adsorptive bubble separation technique developed in recent decades for the treatment of low concentration effluent streams [33]. Lesser energy consumption, low fixed and operating costs, ability to recover solutes from dilute solutions with fairly high efficiency are some of the characteristics which make foam fractionation more feasible in comparison to other conventional techniques [34]. Foam fractionation has already been proved to be an effective technique for
This is an Open Access article distributed under the terms of the Creative Commons Attribution Non-Commercial License (http://creativecommons.org/licenses/by-nc/3.0/) which permits unrestricted non-commercial use, distribution, and reproduction in any medium, provided the original work is properly cited.

Copyright (C) 2021 Korean Society of Environmental Engineers
Received May 15, 2020 Accepted August 04, 2020

${ }^{\dagger}$ Corresponding author

Email: kaushalnaresh74@gmail.com

Tel: +91-7544267051 Fax: +91-7544267051

ORCID: 0000-0002-6885-880X 
the separation of proteins, enzymes, surfactants, and heavy metals [35-37]. Here, the driving force responsible for separation is the difference in the concentration of solute in the bulk liquid and the solute concentration in contact with a gas-liquid interface [38]. The gas-liquid interface is created by sparging air bubbles through an aqueous solution over which preferential adsorption of surface-active species occurs [39]. These air bubbles produce foam above the liquid solution, get enriched in more surface-active species as the foam rises [40]. The foam also carries with it the interstitial liquid due to entrainment, which itself gets liberated into the bulk liquid due to gravity with the upward movement of foam [41]. Finally, the foamate (collapsed foam) obtained from the top of the column, rich in solute is collected and analyzed. Dye removal by foam fractionation technique also requires the presence of a surfactant (act as a collector) as inherently dyes are not surface-active [42]. The addition of surfactant also facilitates the generation of stable foam, necessary for the separation [43]. The dye removal takes place following the formation of the dye-surfactant complex, which gets adsorbed on to the bubble surface. Owing to the above-stated advantages, this technique has been successfully implemented for dye removal in recent times. Literature review, however, reveals that only a few researchers have so far attempted to explore foam fractionation for the separation of dyes viz. removal of methyl orange employing dodecyl dimethyl betaine as a surfactant [44], removal of rhodamine B employing sodium dodecylbenzene sulfonate as a surfactant [45], removal of direct black 17 employing cetyl trimethyl ammonium bromide as a surfactant [42], removal of methylene blue employing sodium dodecyl sulfate as a collector [46] and removal of crystal violet employing sodium dodecyl sulfate as a surfactant [47]. In the view of an extensive literature review, an attempt was made in the present paper to utilize this powerful technique for the removal of dye. In the current study, sodium dodecyl sulfate (SDS), an anionic surfactant has been chosen for the removal of $\mathrm{MB}$ (cationic dye). The performance of the foam fractionation column in the removal of $\mathrm{MB}$ was assessed by evaluating the percentage removal and enrichment ratio. Both parameters are affected by operating variables like aeration rate, liquid height in the column, dye concentration in the feed, $\mathrm{pH}$ of the feed solution and surfactant concentration. In addition to enrichment ratio and percentage removal, surface excess was also evaluated which is usually determined for continuous processes in previous studies. But for semi-batch process, surface excess has been estimated for the first time at varying operating conditions, which is also an essential parameter for the in-depth understanding of adsorption phenomena. Taguchi methodology was employed for the design of experiments by utilizing orthogonal array [48] and subsequently, both percentage removal and enrichment ratio were optimized separately to maximize them. Further, the grey relational analysis was carried out for multi-objective optimization to find out the optimal settings subject to maximization of both percentage removal and enrichment ratio simultaneously, which has never been attempted by any researcher till date. Lastly, heat of desorption studies were also conducted for the first time for dyeing wastewater to establish equilibrium relationship between the dye concentration in bulk liquid phase and foam phase.

\section{Materials and Methods}

\subsection{Chemicals and Analytical Methods}

The chemicals used in this work are $\mathrm{MB}\left(\mathrm{C}_{16} \mathrm{H}_{18} \mathrm{ClN}_{3} \mathrm{~S}\right)$ and SDS $\left(\mathrm{NaC}_{12} \mathrm{H}_{25} \mathrm{SO}_{4}\right)$, procured from Sd fine-Chem Limited, India, of analytical grade.The molecular structure of $\mathrm{MB}$ and SDS along with the formation of SDS-MB complex is shown in Fig. S1. In all the experiments, distilled water was employed in the preparation of solutions. UV-Vis spectrophotometer (Elico SL210 Double beam) was utilized in the determination of $\mathrm{MB}$ concentration in SDS at the maximum absorption wavelength of $610 \mathrm{~nm}$.

\subsection{Experimental Set-Up}

The experimental setup of the semi-batch foam fractionation column for the removal of $\mathrm{MB}$ from wastewater is illustrated in Fig. 1. It comprised a cylindrical glass column with a height and internal diameter of $1.1 \mathrm{~m}$ and $0.05 \mathrm{~m}$, respectively. Air sparger, a sintered glass filter with $100-160 \mu \mathrm{m}$ mean pore diameter, was installed at the bottom of the glass column. Further, to prevent any harm to the sparger at the time of charging of dye solution into the column, two inlet points were provided. Air was introduced with the help of a compressor through the sparger.

\subsection{Experimental Procedure}

All experimental runs commenced with the filling of a feed solution of known concentration into the column up to a fixed height (or volume). Compressed air at a measured flow rate was then allowed to enter at the bottom of the column through air sparger, generated bubbles that ascended to the surface of the liquid and produced foam there. For the estimation of dye concentration employing spectrophotometer, samples of foam through foam draw-off (top

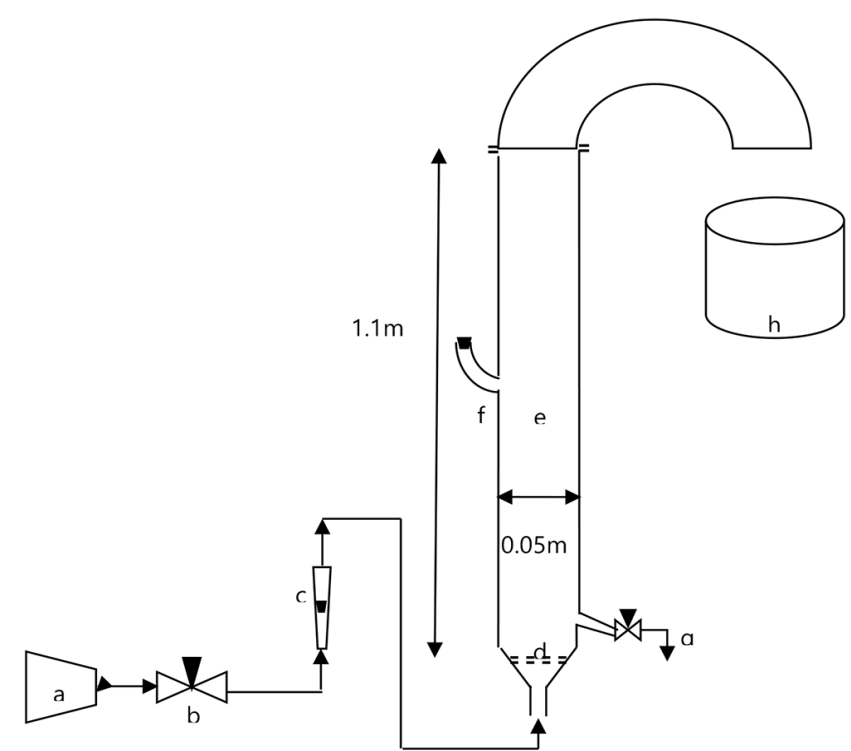

Fig. 1. Schematic diagram of the experimental set-for foam fractionation. (a) Compressor, (b) Needle valve, (c) Flow meter, (d) Air sparger, (e) Foam fractionation column, (f) Feed point, (g) Bottom sampling point, (h) Foam collector. 
of the column) and residual liquid solution (bottom of the column) were collected at fixed time intervals. Before the analysis, foam samples were allowed to collapse. All the experiments were conducted at room temperature $\left(25 \pm 2^{\circ} \mathrm{C}\right)$.

\section{Determining the Parameters}

The performance of the foam fractionation column was assessed by estimating parameters such as percentage removal, enrichment ratio, the wetness of the foam, bubble size, and surface excess; discussed in this section.

\subsection{Separation Efficiency}

Percentage removal and enrichment ratio are the two key parameters related to the separation of a solute (dye) in the foam fractionation column. Percentage removal $(R)$ indicates the reduction in dye concentration (in \%) with respect to dye concentration in the feed solution, expressed as [49-53]:

$$
R=\left(\frac{C_{i}-C_{e}}{C_{i}}\right) \times 100
$$

where $C_{i}$ (ppm) and $C_{e}$ (ppm) are the dye concentration in the feed solution and the remaining liquid solution (bottom of the column), respectively.

Enrichment ratio $(E)$ indicates how many times the foam gets enriched with dye relative to feed concentration, expressed as [49]:

$$
E=\frac{C_{f}}{C_{i}}
$$

where $C_{f}(\mathrm{ppm})$ is the dye concentration in the collapsed foam (foamate).

\subsection{Liquid Hold up at the Exit of the Column}

Liquid hold up which represents wetness of the foam is another important parameter that needs to be found out, as it directly affects the enrichment ratio. It can be found out by using the following expression [54]:

$$
\epsilon_{\text {exit }}=\frac{V_{f}}{V_{f}+V_{g}}
$$

where $V_{g}(\mathrm{~L})$ is the volume of air entering into the column at a given time and $V_{f}(\mathrm{~L})$ is the foamate volume collected in a given time.

\subsection{Bubble Size}

As we know, adsorption of dye takes place on the surface of the bubbles, the bubble diameter must be known for the determination of an interfacial surface area of the bubbles. A photographic technique using a digital camera (Nikon CoolPIX P600) was employed to determine the bubble size distribution. Each image consisting of around 100-200 bubbles was analyzed by using Image J software to enable the evaluation of mean bubble diameter. Sauter's mean diameter $\left(d_{32}\right)$ was found out by using the following expression [49]:

$$
d_{32}=\frac{\sum_{i=1}^{n} d_{i}^{3}}{\sum_{i=1}^{n} d_{i}^{2}}
$$

Here diameter of $i^{\text {th }}$ the bubble is denoted by $d_{i}$ and the number of bubbles per image by $\mathrm{n}$.

\subsection{Surface Excess}

Surface excess is a measure of the amount of dye adsorbed on a unit surface area of the bubble. Following expression was used to calculate surface excess [55]:

$$
\Gamma=\frac{\left(C_{f}-C_{e}\right) V_{f} d_{32}}{0.006 V_{g}}
$$

where $\Gamma$ is the surface excess in mg. $\mathrm{m}^{-2}$.

\section{Experimental Results}

In this section, experiments were performed by operating the foam fractionation column at different operating conditions and the results obtained have been thoroughly discussed. The average bubble size of $0.75 \mathrm{~mm}, 0.8 \mathrm{~mm}$ and $0.87 \mathrm{~mm}$ was obtained at airflow rates of 150, 200 and $250 \mathrm{~mL} \cdot \mathrm{min}^{-1}$, respectively, using Eq. (4).

\subsection{Effect of Contact Time}

In semi-batch foam fractionation, contact time is a significant parameter to ascertain as to how long the column needs to be operated. Hence, to start with, the dependence of both the separation parameters on time was investigated. Fig. 2(a) exhibits one such study, increase in percentage removal and decrease in the enrichment ratio with time was observed when the column was operated at an airflow rate of $200 \mathrm{~mL} \cdot \mathrm{min}^{-1}$, dye concentration of $15 \mathrm{ppm}$ and liquid loading of $750 \mathrm{~mL}$. The optimum time was then found out to be around $25 \mathrm{~min}$, the point where both curves intersect (Fig. 2(a)). The column behavior with respect to time was also investigated at other operating conditions (not shown here) and optimum time in the range of 20 to 25 min was obtained for all the runs. As a result, all the experiments were further carried out for a uniform time of $25 \mathrm{~min}$.

\subsection{Effect of SDS Concentration}

The surfactant concentration has a pronounced effect on the separation of dye in a foam fractionation column, which necessitates the determination of optimum surfactant dose. The effect of surfactant dose (SDS concentration) on the performance of the foam fractionation column was investigated by varying the SDS concentration in the range of 250-2000 ppm. Critical micelle concentration (CMC) of any surfactant is a crucial property in deciding the concentration up to which it can be safely added. As it is a well-known fact that prior to CMC, the surfactant undergoes a huge reduction 
in surface tension and it also shows a weak surface absorptive capacity. Since CMC of SDS is around 2500 ppm owing to which the column was operated till 2,000 ppm. The other operating variables were kept constant, namely, air flow rate, liquid loading and dye concentration of $200 \mathrm{~mL}$. $\mathrm{min}^{-1}, 750 \mathrm{~mL}$, and $15 \mathrm{ppm}$, respectively. It can be seen from Fig. 2(b), the enrichment ratio decreased with the increase in SDS concentration. It may be attributed to the fact that higher SDS concentrations resulted in a decrease in surface tension and an increase in viscosity, due to which liquid hold up in the foam exiting the column increased, eventually led to a decrease in enrichment ratio. On the other hand, the percentage removal initially increased from $65 \%$ to $82 \%$, followed by a declining trend with the increase in SDS concentration (Fig. 2(b)). Higher entrainment of the liquid in the foam phase may be the reason for the initial increase in percentage removal up to an SDS concentration of 700 ppm. Thereafter, a decrease in percentage removal was due to the saturation of the bubble surface with the adsorbed surfactant and the addition of more surfactant would only result in competition with the already formed complexes for vacant space on the air-bubble interface. These results were consistent with one of the previously published works [46]. From Fig. 2(b), the optimum SDS dose was found to be $500 \mathrm{ppm}$ following which all the experiments were conducted at the optimum SDS concentration.

\subsection{Effect of Initial $\mathrm{pH}$}

Variation in the initial $\mathrm{pH}$ of the feed solution causes the concentration of $\mathrm{H}^{+}$and $\mathrm{OH}^{-}$ions to change, which affects the removal of dye in the foam fractionation process. To study the effect of initial $\mathrm{pH}$ of feed solution on percentage removal and enrichment ratio, the column was operated at an airflow rate of $200 \mathrm{~mL} \cdot \mathrm{min}^{-1}$, liquid loading of $750 \mathrm{~mL}$, and dye concentration of $15 \mathrm{ppm}$ by varying the $\mathrm{pH}$ of a feed solution in the range of 3-10, is shown in Fig. 2(c). Feed solutions of different $\mathrm{pH}$ values were prepared by using $0.5 \mathrm{~N} \mathrm{HCl}$ and $0.5 \mathrm{~N} \mathrm{NaOH}$. It is apparent from Fig. 2(c) that enrichment did not vary much $(7.1-7.35)$ with $\mathrm{pH}$, while percentage removal initially increased and fell afterward with the increase in $\mathrm{pH}$. Under both acidic (low $\mathrm{pH}$ ) and alkaline (high $\mathrm{pH}$ ) conditions, the dye-surfactant complex formation becomes difficult due to which percentage removal was found to be low at extreme values of $\mathrm{pH}$. At low $\mathrm{pH}, \mathrm{H}^{+}$ions competed with cationic dye whereas at high $\mathrm{pH}, \mathrm{OH}^{-}$ions competed with an anionic surfactant that was responsible for complex formation in lesser amounts. Poor foam quality and stability at lower $\mathrm{pH}$ while the presence of more water content in the foam phase at higher $\mathrm{pH}$ might also be the reason for lower percentage removal at these conditions [45]. The optimum $\mathrm{pH}$ ranges as seen from Fig. 2(c) is 6.7 to 7.4 . Further, all the experiments were carried out at a $\mathrm{pH}$ of 7 .

\subsection{Effect of Aeration Rate}

The airflow rate greatly affects the quantity of bubbles, their residence time and rate of foam production, which in turn influence both percentage removal and enrichment ratio. Its effect was investigated by operating the column at $750 \mathrm{~mL}$ liquid loading, $15 \mathrm{ppm}$ dye concentration and 500 ppm SDS dose at varying air flow rates $\left(150-250\right.$ mL.min $\left.{ }^{-1}\right)$, which is represented in Fig. 3(a). The percentage removal increased while the enrichment ratio decreased with an increase in airflow rate, which is visible from Fig. 3(a). Higher percentage removal with an increase in the aeration rate was due to the production of a large number of bubbles as a result of which higher surface flux was obtained (surface available for adsorption). On the other hand, a decrease in enrichment ratio with an increase in air flow rate can be explained in terms of the shorter residence time of bubbles in the foam phase causing higher entrainment of liquid along with the bubbles, finally resulting in wet foam.

Fig. 3(b) demonstrates the effect of airflow rate on surface excess and it was found to decrease with the increase in aeration rate. Higher enrichment ratio (more foamate concentration) at lower aeration rates was mainly responsible for greater surface excess which outweighed the advantage of having a higher surface area of bubbles at greater airflow rates.

\subsection{Effect of Liquid Loading}

Altering the liquid height in the column causes the amount of dye present in the liquid solution and residence time to change as a result of which performance of the column gets affected. To investigate its effect, the liquid loading varied from $600-900$ $\mathrm{mL}$ while other parameters such as airflow rate, dye concentration,
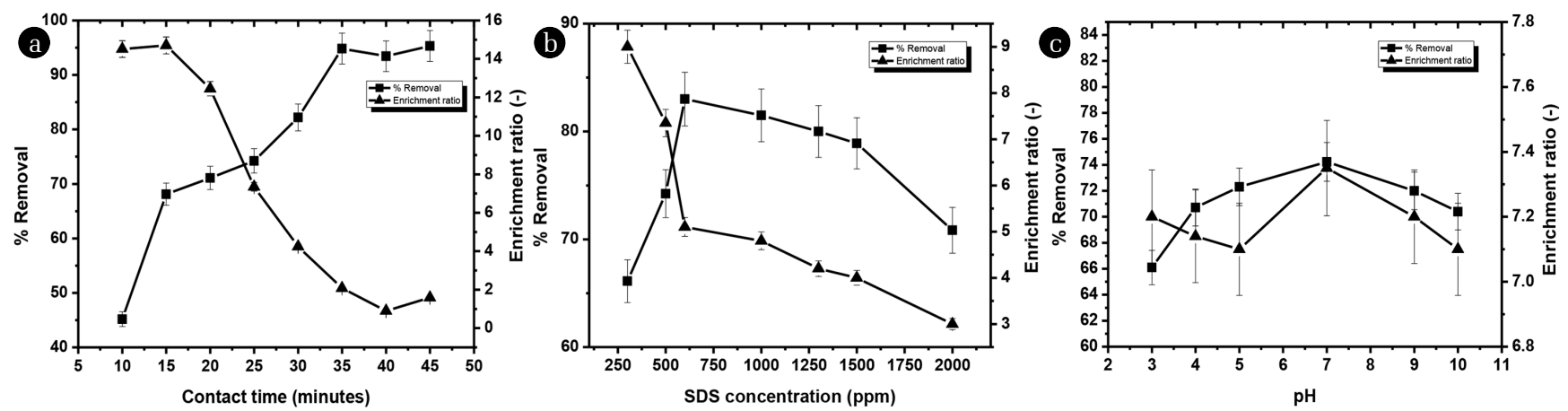

Fig. 2. Variation in percentage removal and enrichment ratio with (a) contact time (Air flow rate $=200 \mathrm{~mL}^{\mathrm{min}}{ }^{-1}$, Liquid loading $=750 \mathrm{~mL}$, Dye concentration $=15 \mathrm{ppm}$, SDS concentration $=500 \mathrm{ppm}$ ) (b) SDS concentration (Air flow rate $=200 \mathrm{~mL}^{\text {min }}{ }^{-1}$, Liquid loading $=750 \mathrm{~mL}$, Dye concentration $=15 \mathrm{ppm}$ ) (c) $\mathrm{pH}$ (Air flow rate $=200 \mathrm{~mL} \cdot \mathrm{min}^{-1}$, Liquid loading $=750 \mathrm{~mL}$, Dye concentration $=15$ ppm, SDS concentration $=500 \mathrm{ppm})$. 
and SDS concentration were maintained constant at $200 \mathrm{~mL} \cdot \mathrm{min}^{-1}$, $15 \mathrm{ppm}$, and $500 \mathrm{ppm}$, respectively. Percentage removal was found to decrease from $85.7 \%$ to $68 \%$ with the increase in liquid loading in the said range (Fig. 3(c)). It may be explained based on two factors working simultaneously on the determination of percentage removal. As already stated, these factors are the amount of dye in the liquid solution and residence time of bubbles. Higher liquid loading resulted in more amount of dye present in the solution as well as greater residence time. Here, an increase in liquid loading caused only a slight increase in the residence time owing to which there was a marginal increase in the adsorption of dye on the bubbles. Finally, the amount of dye (or concentration) left in the residual liquid solution would be more at higher liquid heights resulting in lower percentage removal. In a nutshell, it can be said that extra residence time provided by increasing the liquid height was not sufficient to increase percentage removal. It can also be seen from Fig. 3(c) that the enrichment ratio slightly increased from 7.48 to 7.69 with the increase in liquid loading. Higher dye concentration in the interstitial liquid may be the reason for a marginal increase in the enrichment ratio despite lesser time for drainage in the foam phase at greater liquid loading.

Fig. 3(d) illustrates the effect of surface excess on liquid loading. The increase in surface excess at higher liquid loadings was due to the higher volume of foamate collected from the top of the column in spite of almost constant foamate concentration.

\subsection{Effect of Dye Concentration}

The performance of the foam fractionation column is also profoundly affected by the dye concentration. The effect of dye concentration (Fig. 3(e)) was studied on percentage removal and the enrichment ratio in the range of $5-25 \mathrm{ppm}$, while keeping other input parameters, such as constant air flow rate: $200 \mathrm{~mL} \cdot \mathrm{min}^{-1}$; liquid loading: $750 \mathrm{~mL}$; and SDS concentration: 500 ppm. Fig. 3(e) shows a decrease in the percentage removal of $89 \%$ to $64 \%$ on increasing the dye concentration. Since the contact time provided in all the experimental runs was the same owing to which lesser uptake of the dye by the bubbles occurred at higher dye concentrations finally resulting in the decrease in percentage removal. It is also evident from Fig. 3(e) that by increasing the dye concentration from 10 - 25 ppm, enrichment ratio fell from 7.9 to 3.8 while exceptionally low enrichment value of 4 was observed at a dye concentration of $5 \mathrm{ppm}$. Reduction in enrichment ratio was due to the greater viscosity of the interstitial liquid at higher dye concentrations which led to a drop in the enrichment ratio owing to poor foam drainage. It was further corroborated by comparing the values of $\in_{\text {exit }}$ at a dye concentration of 25 and 10 ppm, respectively (0.025 at 25 ppm and 0.017 at $10 \mathrm{ppm}$ ). The unusual behavior at $5 \mathrm{ppm}$ can be explained by considering the fact that after $25 \mathrm{~min}$ of contact time, the amount of dye remaining in the liquid solution would be meager which resulted in lower enrichment value.
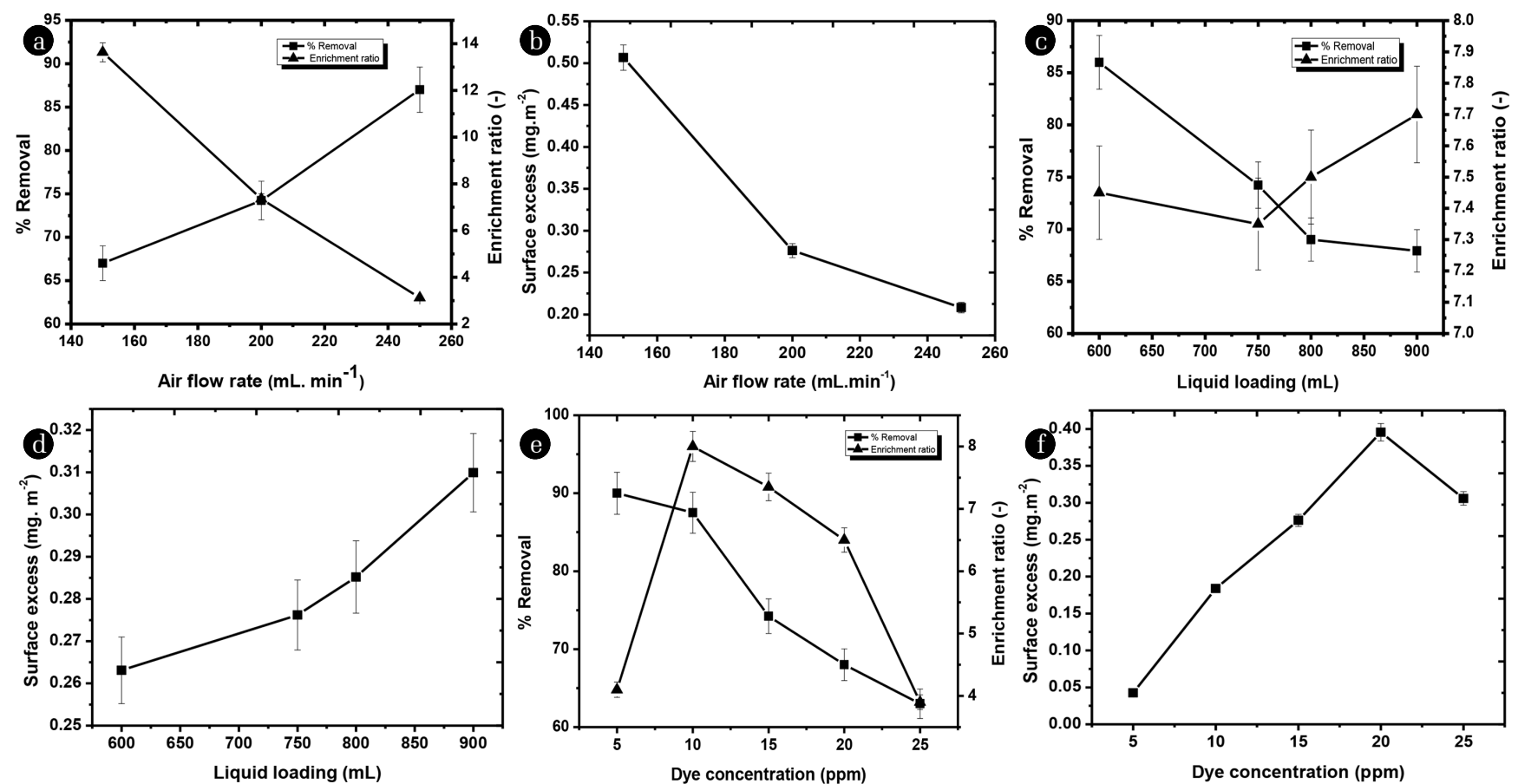

Fig. 3. Effect of air flow rate on (a) percentage removal and enrichment ratio (Liquid loading $=750 \mathrm{~mL}$, Dye concentration $=15 \mathrm{ppm}$, SDS concentration $=500 \mathrm{ppm}$ ), (b) surface excess (Liquid loading $=750 \mathrm{~mL}$, Dye concentration $=15 \mathrm{ppm}$, SDS concentration $=500 \mathrm{ppm}$ ), Effect of liquid loading on (c) percentage removal and enrichment ratio (Air flow rate $=200 \mathrm{~mL}^{\mathrm{min}}{ }^{-1}$, Dye concentration $=15$ ppm, SDS concentration $=500 \mathrm{ppm}$ ) $(\mathrm{d})$ surface excess (Air flow rate $=200 \mathrm{~mL} \cdot \mathrm{min}^{-1}$, Dye concentration $=15 \mathrm{ppm}$, SDS concentration $=500 \mathrm{ppm}$ ), Effect of dye concentration on (e) percentage removal and enrichment ratio (Air flow rate $=200 \mathrm{~mL}^{\mathrm{min}}{ }^{-1}$, Liquid loading $=750 \mathrm{~mL}$, SDS concentration $=500 \mathrm{ppm}$ ) $(\mathrm{f})$ surface excess (Air flow rate $=200 \mathrm{~mL} \cdot \mathrm{min}^{-1}$, Liquid loading $=750 \mathrm{~mL}$, SDS concentration $=500 \mathrm{ppm})$. 
The variation of surface excess with dye concentration is also shown in Fig. 3(f). It increased from 0.041 to $0.396 \mathrm{mg} . \mathrm{m}^{-2}$ on increasing the dye concentration from $5-20 \mathrm{ppm}$. Higher foamate concentration obtained at higher dye concentrations may be the reason for this increasing trend. Further, the surface excess value decreased to $0.305 \mathrm{mg} \cdot \mathrm{m}^{-2}$ at $25 \mathrm{ppm}$ owing to a greater percentage decrease in enrichment ratio.

\section{Taguchi Approach}

The design of experiments (DOE) techniques has been extensively applied nowadays in various industries to enhance the quality of products. The conventional techniques are normally complex, employ one factor at a time approach, keeping other parameters constant, thus with $l$ factors and $k$ levels, the number of experiments amount to $k^{l}$ that needs to be performed. The full factorial design yields $3^{3}$ i.e. 27 experiments in the present study, which is laborious, hence time-consuming. To overcome this problem, Taguchi methodology has been successfully applied for the design of experiments in this work. Also, this technique assumes significance as it is used as a tool for optimizing the operating parameters to obtain the desired response, thus making it a unique variant of DOE. This method makes use of specially designed orthogonal arrays capable of (i) investigating the effect of various operating variables simultaneously, and (ii) considering the entire parameter space at the same time; with a substantially lower number of experiments [56]. A suitable array is first selected which in turn depends upon the number of operating parameters and their respective setting levels. The columns of this orthogonal array denote different operating parameters involved in the process at various setting levels, whereas rows correspond to various combinations of experiments with the levels of different operating parameters. The experimental responses obtained at these conditions are then transformed into a signal-to-noise $(\mathrm{S} / \mathrm{N})$ ratio, a logarithmic function of experimental response, which also acts as an objective function for optimization. According to Taguchi, this ratio measures the quality characteristics drifting from the desired values. For the analysis of the $\mathrm{S} / \mathrm{N}$ ratio, three categories of quality characteristics were proposed, namely, the-smaller-the-better, the-greater-the-better and the-nominal-the-better [57]. The greater $\mathrm{S} / \mathrm{N}$ ratio always corresponds to the best quality characteristics irrespective of the category chosen for the study. Thus the parameter settings, which yield the highest $\mathrm{S} / \mathrm{N}$ ratio are considered to be optimal values of operating parameters. Furthermore, to ascertain the significance of operating parameters statistically, analysis of variance (ANOVA) is carried out. The optimal combination of operating parameters is then subsequently determined using $\mathrm{S} / \mathrm{N}$ values and ANOVA results. The confirmation test is eventually performed at optimal parameters to substantiate them.

To begin with, the Taguchi optimization methodology requires the selection of an appropriate orthogonal array consisting of a discrete number of levels defined for each of the operating parameters. In this context, three operating parameters, namely, air flow rate, liquid loading and dye concentration, in the respective ranges were chosen: $150-250 \mathrm{~mL} \cdot \mathrm{min}^{-1}, 600-900 \mathrm{~mL}$, and 5 - 25 ppm. Three levels for each operating parameter were taken; Table 1 indicates these operating parameters along with their experimental design levels. The expression to estimate the minimum number of experiments required to be conducted in the orthogonal array is as follows [58]:

$$
N_{\min }=(l-1) k+1
$$

where $k$ and $l$ are the number of factors and number of levels, respectively. According to Table 1 , here, $k=3$ and $l=3$, which gives $N_{m i n}=7$. As per Taguchi, the selected orthogonal array must have degrees of freedom equal to greater than $N_{\min }$. In the present study, the L9 orthogonal array was picked that needed 9 experiments to be conducted, shown in Table 2 .

Table 1. Operating Parameters and Their Levels

\begin{tabular}{lcccc}
\hline Symbol & Operating parameters & Level 1 & Level 2 & Level 3 \\
\hline A & Air flow rate $\left(\mathrm{mL} \cdot \mathrm{min}^{-1}\right)$ & 150 & 200 & 250 \\
B & Liquid loading $(\mathrm{mL})$ & 600 & 750 & 900 \\
C & Dye concentration $(\mathrm{ppm})$ & 5 & 15 & 25 \\
\hline
\end{tabular}

Table 2. Experimental Layout Using an L9 Orthogonal Array

\begin{tabular}{lccc}
\hline \multirow{2}{*}{ Experiment No. } & & Operating parameters & \\
\cline { 2 - 3 } & Air flow rate & Liquid loading & Dye concentration \\
\hline 1 & 1 & 1 & 1 \\
3 & 1 & 2 & 2 \\
4 & 1 & 3 & 3 \\
5 & 2 & 1 & 2 \\
6 & 2 & 2 & 3 \\
7 & 2 & 3 & 1 \\
8 & 3 & 1 & 3 \\
9 & 3 & 2 & 1 \\
\hline
\end{tabular}




\subsection{Analysis of $\mathrm{S} / \mathrm{N}$ Ratio for Percentage Removal and Enrichment Ratio}

Prior to the calculation of the $\mathrm{S} / \mathrm{N}$ ratio, nine experiments according to the orthogonal array (Table 2) at different combinations of operating parameters were performed. The experimental responses, i.e. percentage removal and enrichment ratio are listed in Table 3. Now, for the computation of the $\mathrm{S} / \mathrm{N}$ ratio, the higher-the-better category was selected since higher values of both the percentage removal and enrichment ratio were desired. The $\mathrm{S} / \mathrm{N}$ ratio, $\eta$ is determined as follows [59]:

$$
\eta=-10 \log (M \cdot S \cdot D)
$$

where M.S.D is the mean square deviation of the response values. The mean square deviation (M.S.D) can be evaluated by the following expression for the higher-the-better category [59].

$$
\text { M.S. } D=\frac{1}{m} \sum_{i=1}^{m} \frac{1}{R_{i}^{2}}
$$

where $\mathrm{m}$ is the number of tests and $R_{i}$ is the value of the response for the ith test. Subsequent to this, Eqs. (7) - (8) were employed to estimate the values of $\mathrm{S} / \mathrm{N}$ for both percentage removal and enrichment ratio and are listed Table 3. As seen from Table 3, experiment no. 8 (for \% removal) and experiment no. 2 (for enrichment ratio), yields a maximum value of $\mathrm{S} / \mathrm{N}$ ratio, indicating a combination of optimal operating parameters for both the responses. The effect of each operating parameter at different values on both the responses could also be found out owing to the orthogonal nature of the experimental design array. For example, the mean value of the $\mathrm{S} / \mathrm{N}$ ratio for the first operating parameter, air flow rate, can be obtained by averaging the $\mathrm{S} / \mathrm{N}$ ratios for the experiments 1 to 3,4 to 6 and 7 to 9 for both the responses. Similarly, average $\mathrm{S} / \mathrm{N}$ ratios were estimated for the other two operating parameters at all the three levels for both the responses. Table S2 illustrates the mean values of the $\mathrm{S} / \mathrm{N}$ ratio, known as an $\mathrm{S} / \mathrm{N}$ response table for both percentage removal and enrichment ratio. The combination of optimum values of the operating variables can also be found out by picking that level of the operating variable at which the greatest value of the $\mathrm{S} / \mathrm{N}$ ratio was obtained. For getting maximum percentage removal, the optimum combination of operating varia- bles is: airflow rate $=250 \mathrm{~mL} \cdot \mathrm{min}^{-1}$, liquid loading $=600 \mathrm{~mL}$, and dye concentration $=5 \mathrm{ppm}$ (Table S1). Similarly, optimum operating variables for maximum enrichment ratio (Table S1) are: airflow rate $=150 \mathrm{~mL} \cdot \mathrm{min}^{-1}$, liquid loading $=600 \mathrm{~mL}$, and dye concentration $=15 \mathrm{ppm}$. The last column of Table S1 indicates the difference between the maximum and minimum $\mathrm{S} / \mathrm{N}$ ratio obtained for all three operating parameters. These values are indicative of the relative importance of operating variables with respect to the response. The relative importance in the decreasing order with respect to percentage removal and enrichment ratio was found to be: dye concentration, airflow rate, liquid loading, and airflow rate, dye concentration, liquid loading, respectively.

\subsection{Analysis of Variance}

Furthermore, analysis of variance (ANOVA) was applied to investigate the quantitative contribution and significance of all the operating variables towards response. The parameters calculated for ANOVA are described [60]. The total sum of squared deviations was first calculated by using:

$$
S S_{T}=\sum_{i=1}^{i=9}\left(\eta_{i}-\bar{\eta}\right)^{2}
$$

where $\bar{\eta}$ is the mean $\mathrm{S} / \mathrm{N}$ ratio and can be found out by using the following expression:

$$
\bar{\eta}=\frac{1}{9} \sum_{i=1}^{9} \eta_{i}
$$

$S S_{T}$, the total sum of squared deviations consists of two source terms: (i) sum of squared deviations due to each operating parameter $S S_{A}, S S_{B}$ and $S S_{C}$, and (ii) sum of squared error $S S_{e}$. Following expressions were utilized:

$$
\begin{gathered}
S S_{A}=3 \sum_{q=1}^{3}\left(\eta_{A_{q}}-\bar{\eta}\right)^{2}, S S_{B}=3 \sum_{q=1}^{3}\left(\eta_{B_{q}}-\bar{\eta}\right)^{2}, \\
S S_{C}=3 \sum_{q=1}^{3}\left(\eta_{C_{q}}-\bar{\eta}\right)^{2} \\
S S_{e}=S S_{T}-S S_{A}-S S_{B}-S S_{C}
\end{gathered}
$$

Table 3. Experimental results for percentage removal and enrichment ratio along with $S / N$ ratio

\begin{tabular}{lccccc}
\hline $\begin{array}{l}\text { Experiment } \\
\text { No. }\end{array}$ & $\begin{array}{c}\text { Air flow rate } \\
\left(\mathbf{m L}_{\mathbf{m i n}} \mathbf{- 1}\right)\end{array}$ & $\begin{array}{c}\text { Liquid loading } \\
\text { (mL) }\end{array}$ & $\begin{array}{c}\text { Dye concentration } \\
\text { (ppm) }\end{array}$ & $\begin{array}{c}\text { Percentage removal } \\
\text { (S/N ratio) }\end{array}$ & $\begin{array}{c}\text { Enrichment ratio } \\
\text { (S/N ratio) }\end{array}$ \\
\hline 1 & 150 & 600 & 5 & $95.7(39.61)$ & $7.49(17.48)$ \\
2 & 150 & 750 & 15 & $67(36.52)$ & $13.63(22.68)$ \\
3 & 150 & 900 & 25 & $46(33.25)$ & $7.3(17.26)$ \\
4 & 600 & 15 & $86(38.68)$ & $7.45(17.44)$ \\
5 & 200 & 750 & 25 & $63(35.98)$ & $3.9(11.82)$ \\
6 & 200 & 900 & 5 & $81.2(38.19)$ & $3.8(11.59)$ \\
7 & 200 & 600 & 25 & $82(38.27)$ & $2.37(7.49)$ \\
8 & 250 & 750 & 5 & $96(39.64)$ & $1.84(5.29)$ \\
9 & 250 & 900 & 15 & $85(38.58)$ & $3.28(10.31)$ \\
\hline
\end{tabular}


Following expressions were then employed for the estimation of the percentage contribution of each operating parameter towards response:

$$
P C(\%)=\frac{S S_{A}}{S S_{T}} \times 100, \quad \frac{S S_{B}}{S S_{T}} \times 100 \text { and } \frac{S S_{C}}{S S_{T}} \times 100
$$

F-value was then determined to ascertain the significance of all the operating parameters. For this purpose, the mean of squared deviations or variance $(V)$ for all the operating parameters and error was computed by using the following expression:

$$
V_{A}=\frac{S S_{A}}{f_{A}}, V_{B}=\frac{S S_{B}}{f_{B}}, V_{C}=\frac{S S_{C}}{f_{C}}, \text { and } V_{e}=\frac{S S_{e}}{f_{e}}
$$

where $f_{A}, f_{B}, f_{C}$, and $f_{e}$ are the degrees of freedom for airflow rate, liquid loading, dye concentration, and error, respectively. Finally, F values were calculated by using the following expressions:

$$
F_{A}=\frac{V_{A}}{V_{e}}, F_{B}=\frac{V_{B}}{V_{e}}, \text { and } F_{C}=\frac{V_{C}}{V_{e}}
$$

An $\mathrm{F}$ value greater than four signifies a change in the operating parameter has a significant effect on the response.

ANOVA results for percentage removal and enrichment ratio are exhibited in Table S2, after applying Eqs. (9) - (15). All the operating parameters, namely, air flow rate, liquid loading, and dye concentration are significant for the percentage removal (Table S2) whereas, for enrichment ratio, airflow rate and dye concentration are significant, while the change in liquid loading in the range studied has insignificant effect on response (Table S2). The percentage contribution of each operating parameter is also listed in the last column of Table S2, indicating dye concentration (49.73\%) and air flow rate $(78.62 \%)$ as most influencing operating variables for percentage removal and enrichment ratio, respectively.

\subsection{Confirmation Tests}

Confirmatory tests were necessitated to justify whether the $\mathrm{S} / \mathrm{N}$ ratio evaluated at optimal conditions were improved with respect to $\mathrm{S} / \mathrm{N}$ ratios from Table 3 . The optimal values of operating variables for both percentage removal and enrichment ratio were first used in predicting the $\mathrm{S} / \mathrm{N}$ ratio $\left(\eta_{e}\right)$ with the help of the following expression [57]:

$$
\eta_{e}=\bar{\eta}+\sum_{i=1}^{p}\left(\overline{\eta_{l}}-\bar{\eta}\right)
$$

where $\bar{\eta}_{\iota}$ is the mean value of the $\mathrm{S} / \mathrm{N}$ ratio at the optimal level and $p$ is the number of operating parameters. Predicted $\mathrm{S} / \mathrm{N}$ ratio $\left(\eta_{e}\right)$ obtained from Eq. (16) was then verified by operating the foam fractionation column at optimal conditions. Table S3 presents the comparison between predicted and experimentally obtained $\mathrm{S} / \mathrm{N}$ ratios for both percentage removal and enrichment ratio. Up-gradation in the values of both percentage removal and enrichment ratio is apparent from Table S3 relative to the $\mathrm{S} / \mathrm{N}$ ratios obtained from Table 3 .

Taguchi methodology successfully gave a set of optimum conditions to obtain maximum percentage removal and enrichment ratio, taking one response at a time. Both percentage removal and enrichment ratio cannot be optimized simultaneously by using this technique due to the non-availability of any method for the assignment of appropriate weights to both the responses. In this work, the grey relational analysis was used for multi-objective optimization, discussed in the following section.

\section{Grey Relational Analysis}

Grey relational analysis, a powerful tool to optimize any process involving more than one response, is used nowadays in various fields of engineering. Hence, it is also known as a multi-objective optimization technique. This technique has been implemented in the present study to determine optimum conditions subjected to the maximization of both percentage removal and enrichment ratio simultaneously. Pre-processing of the experimental data was first carried out to transform it into a comparable sequence from the original sequence. This transformation is purposely done to nullify the effect of different units of the responses associated with any process. One such method is the normalization of data, also called grey relational generating which converts all the values of experimental responses between 0 and 1 , can be done by utilizing the following expressions [61]:

Lower is better:

$$
X_{i}^{*}(k)=\frac{\max X_{i}(k)-X_{i}(k)}{\max X_{i}(k)-\min X_{i}(k)}
$$

Higher is better:

$$
X_{i}^{*}(k)=\frac{X_{i}(k)-\min X_{i}(k)}{\max X_{i}(k)-\min X_{i}(k)}
$$

Nominal is better:

$$
X_{i}^{*}=1-\frac{\left|X_{i}(k)-X_{0 b}(k)\right|}{\max X_{i}(k)-X_{0 b}(k)}
$$

where $i=1,2,3, \ldots \ldots, n$ with $n$ number of experiments; $k=1$, $2,3, \ldots \ldots, p$ with $p$ number of responses; $X_{i}^{*}$ is the normalized value of the $k$ th element in ith sequence; $\min X_{i}(k)$ and $\max X_{i}(k)$ are known as a minimum and maximum value of $X_{i}(k)$, respectively.

As already mentioned, higher values of both percentage removal and enrichment ratio were intended in this work; Eq. (18) was used for the normalization of data.

Next, grey relational coefficients (GRC) relating ideal and normalized (actual) experimental results were found out with the help of the expression given by [61]:

$$
\xi_{0, i}(k)=\frac{\Delta \min +\zeta . \Delta \max }{\Delta_{0, i}(k)+\zeta . \Delta \max }, \quad i=1, \ldots . . n ; k=1,2 \ldots . p .
$$

where $\xi_{0, i}(k)$ denotes the difference between the $k$ th element of the reference sequence $X_{0}$ and comparative sequence $X_{i} ; \triangle_{0, i}(k)$ represents the difference between $X_{i}(k)$ \& $X_{0}(k)$.

$$
\Delta_{0, i}(k)=\left|X_{0}^{*}(k)-X_{i}^{*}(k)\right|
$$




$$
\begin{gathered}
\Delta \max =\max _{i} \max _{k}\left|X_{0}^{*}(k)-X_{i}^{*}(k)\right| \\
\Delta \min =\min _{i} \min _{k}\left|X_{0}^{*}(k)-X_{i}^{*}(k)\right|
\end{gathered}
$$

where $\zeta$ is the distinguishing coefficient and its value was considered to be 0.5 in further calculations [62].

\subsection{Weight Calculation}

The weights of all the responses involved in the process are necessary to enable the estimation of grey relational grade from grey relational coefficients. In most of the earlier works, grey relational grade was simply found out by taking the average value of grey relational coefficients of all the responses. Here, an entropy measurement method was employed to access the weight of each response owing to the varying importance of all the responses involved in the process. According to information theory, entropy is defined as a measure of disorder in the process. The application of the entropy concept in weight measurement tells us that the attributes with larger entropies have a notable effect on the response. Entropy, as a mapping function is defined as $f_{i}:[0,1] \rightarrow[0,1]$ and should satisfy the following conditions: (1) $f_{i}(0)=0$, (2) $f_{i}(x)=f_{i}(1-x)$, (3) $f_{i}(x)$ is monotonic increasing in the range of $x \in(0,0.5)$ [63]. The following mapping function can thus be used for entropy measurement.

$$
w_{e}(x)=x e^{(1-x)}+(1-x) e^{x}-1
$$

The maximum value of the above function is found to be 0.6478 evaluated at $x=0.5$. Entropy function can now be written as:

$$
W \equiv \frac{1}{\left(e^{0.5}-1\right) n} \sum_{i=1}^{n} w_{e}\left(x_{i}\right)
$$

The step-by-step entropy measurement procedure for all the responses involved in the process is given below [63]:

(a)Total of grey relational coefficients for each response in all sequences:

$$
D_{j}=\sum_{i=1}^{n} \xi_{i}(j), \quad j=1,2, \ldots, p .
$$

(b) Normalized coefficient:

$$
k=\frac{1}{\left(e^{0.5}-1\right) n}=\frac{1}{0.6487 n}
$$

(c) The entropy of each response:

$$
e_{j}=k \sum_{i=1}^{n} w_{e}\left(\frac{\xi_{i}(j)}{D_{j}}\right), \quad j=1,2, \ldots, p .
$$

(d) Summation of entropies of all the responses:

$$
E=\sum_{j=1}^{p} e_{j}
$$

(e) Weight of each response:

$$
w_{j}=\frac{1 / p-E\left[1-e_{j}\right]}{\sum_{j=1}^{p} 1 / p-E\left[1-e_{j}\right]}, \quad i=1,2, \ldots \ldots . .
$$

Finally, following expression after the calculation of the weight of each response provides the values of grey relational grade (GRG):

$$
\Gamma_{0, i}=\sum_{k=1}^{p} w_{k} \xi_{0, i}(k), \quad i=1,2, \ldots \ldots . . n .
$$

\subsection{Results and Discussion}

GRG was estimated after computing normalized sequences, deviation sequences and GRC by using Eqs. (17) - (31). The weights assigned to both percentage removal and enrichment ratio

were 0.53113 and 0.4688 , respectively. Table 4 summarized the values of all these parameters. The highest rank 1 corresponding to the largest value of the grey relational grade (experiment no. 1, Table 4) indicates the set of operating conditions at which maximum values of both percentage removal and enrichment ratio can be achieved simultaneously. The same values of optimum

\begin{tabular}{|c|c|c|c|c|c|c|c|c|}
\hline \multirow{2}{*}{$\begin{array}{l}\text { Experimental } \\
\text { Run }\end{array}$} & \multicolumn{2}{|c|}{ Normalized sequences } & \multicolumn{2}{|c|}{ Deviation Sequences } & \multicolumn{2}{|c|}{ GRC } & \multirow{2}{*}{ GRG } & \multirow{2}{*}{ Rank } \\
\hline & $\% \mathrm{R}$ & $\mathbf{E}$ & $\% R$ & $\mathbf{E}$ & $\% \mathbf{R}$ & $\mathbf{E}$ & & \\
\hline 1 & 0.994 & 0.47922 & 0.006 & 0.52078 & 0.988142 & 0.489821 & 0.75446 & 1 \\
\hline 2 & 0.42 & 1 & 0.58 & 0 & 0.462963 & 1 & 0.714694 & 2 \\
\hline 3 & 0 & 0.463104 & 1 & 0.536896 & 0.333333 & 0.482209 & 0.403103 & 9 \\
\hline 4 & 0.8 & 0.475827 & 0.2 & 0.524173 & 0.714286 & 0.488199 & 0.608246 & 4 \\
\hline 5 & 0.34 & 0.174724 & 0.66 & 0.825276 & 0.431034 & 0.37728 & 0.405804 & 8 \\
\hline 6 & 0.704 & 0.166243 & 0.296 & 0.833757 & 0.628141 & 0.374881 & 0.509368 & 6 \\
\hline 7 & 0.72 & 0.044953 & 0.28 & 0.955047 & 0.641026 & 0.343632 & 0.501562 & 7 \\
\hline 8 & 1 & 0 & 0 & 1 & 1 & 0.333333 & 0.687397 & 3 \\
\hline 9 & 0.78 & 0.122137 & 0.22 & 0.877863 & 0.694444 & 0.362881 & 0.538959 & 5 \\
\hline
\end{tabular}
operating variables for the removal of dye in a foam fractionation column were obtained from Table S4 prepared by computing average values of grey relational grades at each experimental level for all the operating variables. Also, Table S4 shows the most prominent and least sensitive input variable with respect to both the responses. Dye concentration was found to have a maximum effect while the airflow rate had the least effect on response. Finally, ANOVA

Table 4. Sequences of Each Response after Data Preprocessing, Grey Relational Coefficient (GRC), Grey Relational Grade (GRG) and Rank of Each Experiment 
was applied to find out the percentage contribution of each operating variable on the response and dye concentration with 59.76\% (Table S5) was found to have the greatest effect on both percentage removal and enrichment ratio.

\section{Heat of Desorption}

The heat of desorption $(\lambda)$ was also evaluated to establish the equilibrium relationship between the dye concentration in the bulk phase and the foam phase [64]. There is a direct analogy between the batch distillation and the batch foaming process. Based on this principle, the following expression was deduced by taking into account the foaming of the differential amount of liquid [65, 66]:

$$
\ln \frac{V_{0}}{V}=\frac{1}{\left(e^{\lambda / R T}-1\right)}\left[\ln \frac{C_{i}}{C_{e}}\right]
$$

Eq. (32) enables the calculation of $\lambda\left(\right.$ cal.mol $\left.^{-1}\right)$. Here, $V_{0}$ and $V$ are the volume of bulk liquid at time $\mathrm{t}=0$ and after time $\mathrm{t}$. $\mathrm{R}$ is the gas constant $\left(1.987 \mathrm{cal} \cdot \mathrm{mol}^{-1} \cdot \mathrm{K}^{-1}\right)$ and $\mathrm{T}$ is the temperature in $K$. After calculating $\lambda$, an equilibrium relationship was found out by the following expression [67]:

$$
C_{f}=\left(e^{\lambda / R T}\right) C_{e}
$$

Now, for the estimation of $\lambda$ experimentally, foaming was carried out sufficiently slowly to ensure equilibrium between surface phase and bulk phase [67]. The variation in liquid volume with dye concentration in the column was noted down at different times following which the graph plotted between $\ln \frac{V_{0}}{V}$ and $\ln \frac{C_{i}}{C_{e}}$ yielded a straight line (Fig. 4) and through the slope of which value of $\lambda$ was found out [68]. The value of $\lambda$ came out to be $2408 \mathrm{cal}^{\mathrm{mol}}{ }^{-1}$ and finally, the equilibrium relationship is given by:

$$
C_{f}=(60.44) C_{e}
$$

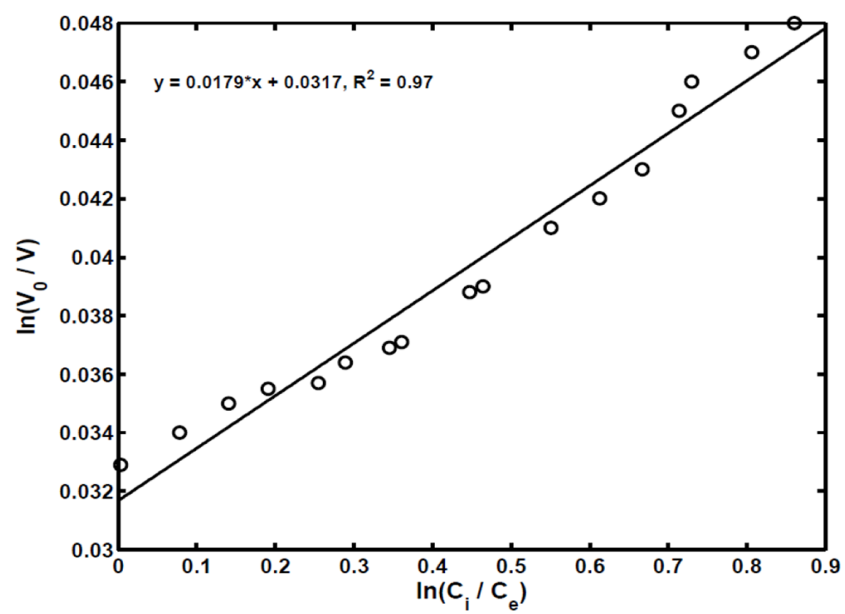

Fig. 4. In $\left(V_{0} / V\right)$ vs. In $\left(C_{i} / C_{e}\right)$ curve for $(\lambda)$ determination (Liquid loading $=750 \mathrm{~mL}$, Dye concentration $=15$ ppm, SDS concentration $=500 \mathrm{ppm})$

\section{Conclusions}

The foam fractionation technique was adopted for the removal of $\mathrm{MB}$ dye from wastewater with the help of SDS as a collector, which was found to be successful in forming a complex with the dye. Dye removal can be enhanced by operating the foam fractionation column at greater air flow rates. This technique was found to be suitable for treatemtnt of dyeing wastewater at low dye concentrations. The removal of dye, with respect to liquid loading, depends upon two competing factors: (i) amount of dye in the liquid solution and (ii) residence time. In the present study, percentage removal first dropped with rise in liquid level and then became almost constant after $800 \mathrm{~mL}$ liquid loading. Grey-based Taguchi methodology was then employed to search for optimal set of conditions which ensured maximum percentage removal (95.7\%) and maximum enrichment ratio (7.49), simultaneously. The order of importance of the operating variables was dye concentration, liquid loading, and air flow rate. The higher heat of desorption $(\lambda)$ value indicated $\mathrm{MB}$ concentration in the foamate to be 60 times the concentration in residual liquid solution, at equilibrium.

\section{Author Contributions}

T.K.B. (Ph.D. student) conducted all the experiments. K.N.G. (Assistant Professor) analyzed the results and helped the student in writing the paper.

\section{References}

1. Benhouria A, Islam MA, Zaghouane-Boudiaf $\mathrm{H}$, Boutahala $\mathrm{M}$, Hameed BH. Calcium alginate-bentonite-activated carbon composite beads as highly effective adsorbent for methylene blue. Chem. Eng. J. 2015;270:621-630.

2. Pei Y, Wu X, Xu G, et al. Tannin-immobilized cellulose microspheres as effective adsorbents for removing cationic dye (methylene blue) from aqueous solution. J. Chem. Technol. Biotechnol. 2017;92:1276-1284.

3. Dehghani MH, Naghizadeh A, Rashidi A, Derakhshani E. Adsorption of reactive blue 29 dye from aqueous solution by multiwall carbon nanotubes. Desalin. Water Treat. 2013;51:7655-7662.

4. Dehghani MH, Dehghan A, Najafpoor A. Removing reactive red 120 and 196 using chitosan/zeolite composite from aqueous solutions: Kinetics, isotherms, and process optimization. J. Ind Eng. Chem. 2017;51:185-195.

5. Shaul GM, Holdsworth TJ, Dempsey CR, Dostal KA. Fate of water soluble azo dyes in the activated sludge process. Chemosphere 1991;22:107-119.

6. Lee JW, Choi SP, Thiruvenkatachari R, Shim WG, Moon H. Evaluation of the performance of adsorption and coagulation processes for the maximum removal of reactive dyes. Dyes Pigments. 2006;69:196-203.

7. Carneiro PA, Umbuzeiro GA, Oliveira DP, Zanoni MVB. Assesssment of water contamination caused by a mutagenic textile effluent/dyehouse effluent bearing disperse dyes. $J$. 
Hazard. Mater. 2010;174:694-699.

8. Ciullini I, Till S, Scozzafava A, Briganti F. Fungal laccase, cellobiose dehydrogenase and chemical mediators: combined actions for the decolorization of different classed of textile dyes. Bioresour. Technol. 2008;99:7003-7010.

9. Bayramoglu G, Altintas B, Arica MY. Immobilization of laccase onto poly (glycidyl-methacrylate) bush grafted poly(hydroxy-ethylmethacrylate) films: enzymatic oxidation of phenolic compounds. Mater. Sci. Eng. C. 2009;69:189-196.

10. Pavan FA, Dias SLP, Lima EC, Benvenutti EV. Removal of Congo Red from Aqueous Solution by Anilinepropylsilica Xerogel. Dyes Pigments. 2008;76:64-69.

11. Hamdi Gad MH, Ashraf El-Sayed A. Activated carbon from agricultural by-products for the removal of Rhodamine-B from aqueous solution. J. Hazard. Mater. 2009;168:1070-1081.

12. Seshadri S, Bishop PL, Agha AM. Anaerobic/aerobic treatment of selected azo dyes in wastewater. Waste. Manage. 1994;14: 127-137.

13. Parida KM, Sahu S, Reddy KH, Sahoo PC. A kinetic, thermodynamic, and mechanistic approach toward adsorption of methylene blue over water-washed manganese nodule leached residues. Ind. Eng. Chem. Res. 2011;50:843-848.

14. Gupta VK, Kumar R, Nayak A, Saleh TA, Barakat MA. Adsorptive removal of dyes from aqueous solution onto carbon nanotubes: a review. Adv. Colloid. Interface. Sci. 2013;193-194:24-34.

15. Gadekar MR, Ahammed MM. Modelling dye removal by adsorption onto water treatment residuals using combined response surface methodology-artificial neural network approach. J. Environ. Manage. 2019;231:241-248.

16. Yavuz E, Bayramoglu G, Arica MY, Senkal BF. Preparation of poly (acrylic acid) containing core-shell type resin for removal of basic dyes. J. Chem. Technol. Biotechol. 2011;86:699-705.

17. Lewis DM. Coloration in the next century. Rev. Prog. Coloration. 1999;29:23-28.

18. Slokar YM, Majcen A, Marechal Le. Methods of decoloration of textile wastewaters. Dyes Pigments. 1998;37:335-356.

19. Gusmao KAG, Gurgel LVA, Melo TMS, Gil LF. Application of succinylated sugarcane bagasse as adsorbent to remove methylene blue and gentian violet from aqueous solutions-Kinetic and equilibrium studies. Dyes Pigments. 2012;92: 967-974.

20. El-Zawahry MM, Abdelghaffar F, Abdelghaffar RA, Hassabo AG. Equilibrium and kinetic models on the adsorption of reactive black 5 from aqueous solution using eichhornia crassipes/chitosan composite. Carbohydr. Polym. 2016;136:507-515.

21. Valliammai S, Subbareddy Y, Nagaraja KS, Jeyaraj B. Removal of methylene blue from aqueous solution by activated carbon of Vigna Mungo L and Paspalum scrobiculatum: Equilibrium, kinetics and thermodynamic studies. Indian J. Chem. Technol. 2017;24:134-144.

22. He Y, Li G, Wang H, Zhao J, Su H, Huang Q. Effect of operating conditions on separation performance of reactive dye solution with membrane process. J. Membr. Sci. 2008;321:183-189.

23. Kokabian B, Bonakdarpour B, Fazel S. The effect of salt on the performance and characteristics of a combined anaerobic-aerobic biological process for the treatment of synthetic wastewaters containing Reactive Black 5. Chem. Eng. J. 2013;221:363-372.
24. Guo S, Hu M, Guo Q, et al. Primary sources and secondary formationof organic aerosols in Beijing, China. Environ. Sci. Technol. 2012;46:9846-9853.

25. Kuppusamy S, Venkateswarlu K, Thavamani P, Lee YB, Naidu $\mathrm{R}$, Megharaj M. Quercusrobur acorn peel as a novel coagulating adsorbent for cationic dye removal from aquatic ecosystems. ECol. Eng. 2017;101:3-8.

26. Riera-Torres M, Gutierrez-Bouzan C, Crespi M. Combination of coagulation-flocculation and nanofiltration techniques for dye removal and water reuse in textile effluents. Desalination 2010;252:53-59.

27. Mittal A, Mittal J, Malviya A, Gupta VK. Adsorptive removal of hazardous anionic dye "Congo red" from wastewater using waste materials and recovery by desorption. J. Colloid. Interface. Sci. 2009;340:16-26.

28. Xu Y, Jin JJ, Li XL, et al. Fabrication of hybrid magnetic HKUST-1 and its highly efficient adsorption performance for congo red dye. RSC Adv. 2015;5:19199-19202.

29. Akar ST, Alp T, Yilmazer D. Enhanced adsorption of acid red 88 by an excellent adsorbent prepared from alunite. J. Chem. Technol. Biotechnol. 2013;88:293-304.

30. Zhao L, Yuan SW. Recognition and selective adsorption of pesticides by superparamagnetic molecularity imprinted polymer naonspheres. RSC Adv. 2016;6:49401-49410.

31. Daneshwar N, Ayazloo M, Khataee AR, Pourhassan M. Biological decolorization of dye solution containing malachite green by microalgae cosmarium sp. Bioresour. Technol. 2007;98: 1176-1182.

32. Gkotsis PK, Banti DC, Peleka EN, Zouboulis AI, Samaras PE. Fouling issues in membrane bioreactors (MBRs) for wastewater treatment: major mechanisms, prevention and control strategies. Processes 2014;2(4):795-866.

33. Merz J, Burghoff B, Zorn H, Schembecker G. Continuous foam fractionation: Performance as a function of operating variables. Sep. Purif. Tech. 2011:82:10-18.

34. Kou QY, Li J, Zhao B, Wu ZL. Recovery of streptomycin sulfate from the wastewater using foam fractionation coupled with adsorption separation for reusing sodium dodecyl sulfate. J. Chem. Technol. Biotechnol. 2015;90:874-879.

35. Uraizee F, Narsimhan G. Effects of kinetics of adsorption and coalescence on continuous foam concentration of proteins comparison of experimental results with model predictions. Biotechnol. Bioeng. 1996;51:384-398.

36. Lockwood CE, Bummer PM, Jay M. Purification of proteins using foam fractionation. Pharm. Res. 1997;14:1511-1515.

37. Stowers CC, Makarov V, Walker A, Edwards RA, Tanner RD. Effect of air flow rate on the foam fractionation of a mixture of egg white and egg yolk. Asia Pac. J. Chem. Eng. 2009;4:180-183.

38. Nielsen DR, Hopmans JW, Kutilek M, Wendroth O. A brief review of soil water, solute transport and regionalized variable analysis. Sci. agric. (Piracicaba, Braz.). 1997;54:89-115.

39. Rajagopalan R, Hirtzel CS. Equilibrium Structure and Properties of Colloidal Dispersions. The Structure, Dynamics and Equilibrium Properties of Colloidal Systems, Springer:Dordrecht; 1990. p.619-633.

40. Rosa PTV, Santana CC, Carbonell RG. Determination of the liquid pool surfactant and protein concentration for semi-batch 
foam fractionation columns. Braz. J. Chem. Eng. 2007;24(1):1-14. 41. Nguyen AV, Harvey PA, Jameson GJ. Influence of gas flow rate and frothers on water recovery in a froth column. Miner. Eng. 2003;16(11):1143-1147.

42. Lu K, Zhang XL, Zhao YL, Wu ZL. Removal of color from textile dyeing wastewater by foam fractionation. J. Hazard. Mater. 2010;182:928-932.

43. Varade D, Carriere D, Arriaga LR, Fameau AL, Rio E, Langevin D, Drenckhan W. On the origin of the stability of foams made from catanionic surfactant mixtures. Soft Matter. 2011;7(14): 6557.

44. Zhang Z, Wu Z, Liu G. Interfacial adsorption of methyl orange in liquid phase of foam fractionation using dodecyl dimethyl betaine as the collector. J. Ind. Eng. Chem. 2015;28:184-189.

45. Fei X, Li W, Zhu S, Liu L, Yang Y. Simultaneous treatment of dye wastewater and surfactant wastewater by foam separation: Experimental and mesoscopic simulation study. Sep. Sci. Technol. 2017;53:1604-1610.

46. Zhang D, Zeng G, Huang J, Bi W, Gengxin X. Spectroscopic studies of dye-surfactant interactions with the co-existence of heavy metal ions for foam fractionation. J. Environ. Sci. 2012;24:2068-2074.

47. Lu K, Li R, Wu Z, Hou K, Du X, Zhao Y. Wall effect on rising foam drainage and its application to foam separation. Sep. Purif. Technol. 2013;118:710-715.

48. Alijerf L. High-efficiency extraction of bromocresol purple dye and heavy metals as chromium from industrial effluent by adsorption onto a modified surface of zeolite: kinetics and equilibrium study. J. Environ. Manage. 2018;225:120-132.

49. Tadakamalla K, Marathe KV. Hydrodynamic study and optimization strategy for the surfactant recovery from aqueous solutions. Desalination 2011;266:98-107.

50. Dehghani MH, Shayeghi M, Yousefi M, Heidarinejad Z, Agarwal S, Gupta VK. High-performance removal of diazinon pesticide from water using multi-walled carbon nanotubes. Microchem. J. 2019;145:486-491.

51. Dehghani MH, Yetilmezsoy K, Salari M, Heidarinejad Z, Yousefi M, Sillanpaa M. Adsorptive removal of cobalt(II) from aqueous solutions using multi-walled carbon nanotubes and $\gamma$-alumina as novel adsorbents: Modelling and optimization based on response surface methodology and artificial neural network. J. Mol. Liq. 2020;299:112154.

52. Dehghani MH, Faraji M, Mohammadi M, Kamani $H$. Optimization of fluoride adsorption onto natural and modified pumice using response surface methodology: Isotherm, kinetic and thermodynamic studies. Korean J. Chem. Eng. 2017;34: 454-462.

53. Dehghani MH, Tajik S, Panahi A, et al. Adsorptive removal of noxious cadmium from aqueous solutions using urea-form- aldehyde: A novel polymer adsorbent. MehodsX 2018;5:1148-1155.

54. Wu Z, Shu T, Zhang M, Liu W. Foam fractionation for effective recovery of leaf protein from alfalfa (Medicago sativa L.). Sep. Sci. Technol. 2020;55:1388-1397.

55. Stevenson P, Xueliang L. Foam fractionation: Principles and process design; CRC Press: New York; 2014. p.177-178.

56. Suresh S, Srivastava VC, Mishra IM. Adsorptive removal of aniline by granular activated carbon from aqueous solutions with catechol and resorcinol. Environ. Technol. 2012;33:773-781.

57. Tutar M, Aydin H, Yuce C, Yavuz N, Bayram A. The optimization of process parameters for friction stir spot-welded AA3003-H12 aluminium alloy using a taguchi orthogonal array. Mater. Des. 2014;63:789-797.

58. Badkar DS, Pandey KS, Buvanashekaran G. Parameter optimization of laser transformation hardening by using taguchi method and utility concept. Int. J. Adv. Manuf. Technol. 2011;52:1067-1077.

59. Pandey AK, Dubey AK. Taguchi based fuzzy logic optimization of multiple quality characteristics in laser cutting of duralumin sheet. Opt. Laser Eng. 2012;50:328-335.

60. Tsai MJ, Li CH. The use of grey relational analysis to determine laser cutting parameters for QFN packages with multiple performance characteristics. Opt. Laser Technol. 2009;41:914-921.

61. Sharma A. Yadava V. Optimization of cut quality characteristics during Nd: YAG laser straight cutting of Ni-based superalloy thin sheet using grey relational analysis with entropy measurement. Mater. Manuf. Processes. 2011;26:1522-1529.

62. Chen CC, Tsao CC, Lin YC, Hsu CY. Optimization of the sputtering process parameters of GZO films using the grey-Taguchi method. Ceram. Int. 2010;36:979-988.

63. Wen KT, Chang TC, You ML. The grey entropy and its application in weighting analysis. In: IEEE International Conference on Systems, Man, and Cybernetics; 14 October 1998; San Diego. p. 1842-1847.

64. Adeyi AA, Jamil NAM, Abdullah LC, Choong TSY. Adsorption of Malachite Green dye from liquid phase using hydrophilic Thiourea-Modified Poly(acrylonitrile-co-acrylic acid): kinetic and isotherm studies. J. Chem. 2019;1:1-14.

65. Saleh ZS, Hossain MM. A study of the separation of proteins from multicomponent mixtures by a semi-batch foaming process. Chem. Eng. Process. 2001;40:371-378.

66. Mukhopadhyay G, Khanam J, Nanda A. Protein removal from whey waste by foam fractionation in a batch process. Sep. Sci. Technol. 2010;45:1331-1339.

67. Lemlich R. Adsorptive bubble separation techniques; Academic Press:New York; 1972.p.161-169.

68. Datta PK, Mukhopadhayay G, Ghosh A. HPLC quantification of lactoperoxidase in therapeutic dairy waste enriched by bubble separation. Int. J. App. Pharm. 2019;11:65-75. 